\title{
Cytokinesis in Animal Cells
}

\author{
Pier Paolo D'Avino ${ }^{1}$, Maria Grazia Giansanti ${ }^{2}$, and Mark Petronczki ${ }^{3}$ \\ ${ }^{1}$ Department of Pathology, University of Cambridge, Cambridge CB2 1QP, United Kingdom \\ ${ }^{2}$ Istituto di Biologia e Patologia Molecolari c/o Dipartimento di Biologia e Biotecnologie, Università Sapienza \\ di Roma, 00185 Roma, Italy \\ ${ }^{3}$ Cell Division and Aneuploidy Laboratory, Cancer Research UK-London Research Institute, Clare Hall \\ Laboratories, South Mimms, Hertfordshire EN6 3LD, United Kingdom \\ Correspondence: ppd21@cam.ac.uk
}

Cell division ends with the physical separation of the two daughter cells, a process known as cytokinesis. This final event ensures that nuclear and cytoplasmic contents are accurately partitioned between the two nascent cells. Cytokinesis is one of the most dramatic changes in cell shape and requires an extensive reorganization of the cell's cytoskeleton. Here, we describe the cytoskeletal structures, factors, and signaling pathways that orchestrate this robust and yet highly dynamic process in animal cells. Finally, we discuss possible future directions in this growing area of cell division research and its implications in human diseases, including cancer.

$\mathrm{C}$ tokinesis is the final step of cell division during which the two daughter cells become physically separated. It begins right after chromosome segregation in anaphase, when a cytokinetic or cleavage furrow forms at the equatorial cortex and ingresses inward to bisect the mother cell, and terminates with the physical detachment of the two daughter cells (Fig. 1). This process involves a finely regulated series of events that ensure equal distribution of genomic and, in the case of symmetric divisions, cytoplasmic material between the two nascent daughter cells. Cytokinesis is crucial because its failure essentially nullifies all of the previous mitotic events, such as chromosome alignment and segregation, and causes polyploidy, which, in turn, can lead to subsequent defective mitoses and chromosomal instability. Like many other cell division processes, cytokinesis is necessary for proper growth and development in many organisms. Moreover, its deregulation has been linked to various diseases, including cancer, blood disorders, female infertility, Lowe syndrome, and age-related macular degeneration (Lacroix and Maddox 2012). Here, we describe the key mechanisms, factors, and signals that control the various cytokinetic events in animal cells, from cleavage site positioning to the final abscission of the two daughter cells.

\section{POSITIONING THE DIVISION \\ PLANE: MICROTUBULES LEAD THE WAY}

The first priority of a dividing cell after anaphase onset is to position the division plane between

Editors: Mitsuhiro Yanagida, Anthony A. Hyman, and Jonathon Pines

Additional Perspectives on Mitosis available at www.cshperspectives.org

Copyright (C) 2015 Cold Spring Harbor Laboratory Press; all rights reserved; doi: 10.1101/cshperspect.a015834

Cite this article as Cold Spring Harb Perspect Biol 2015;7:a015834 
P.P. D'Avino et al.

Early telophase

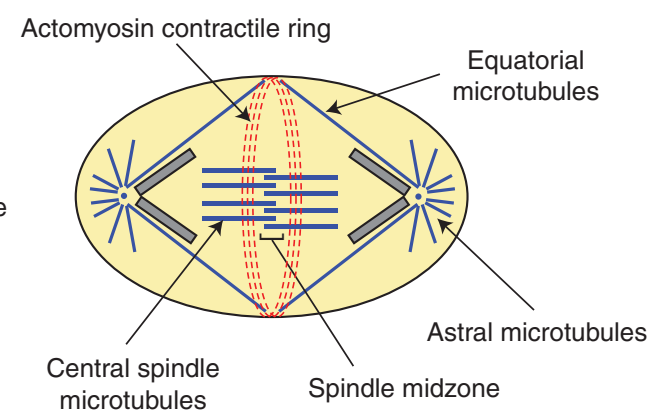

Late telophase
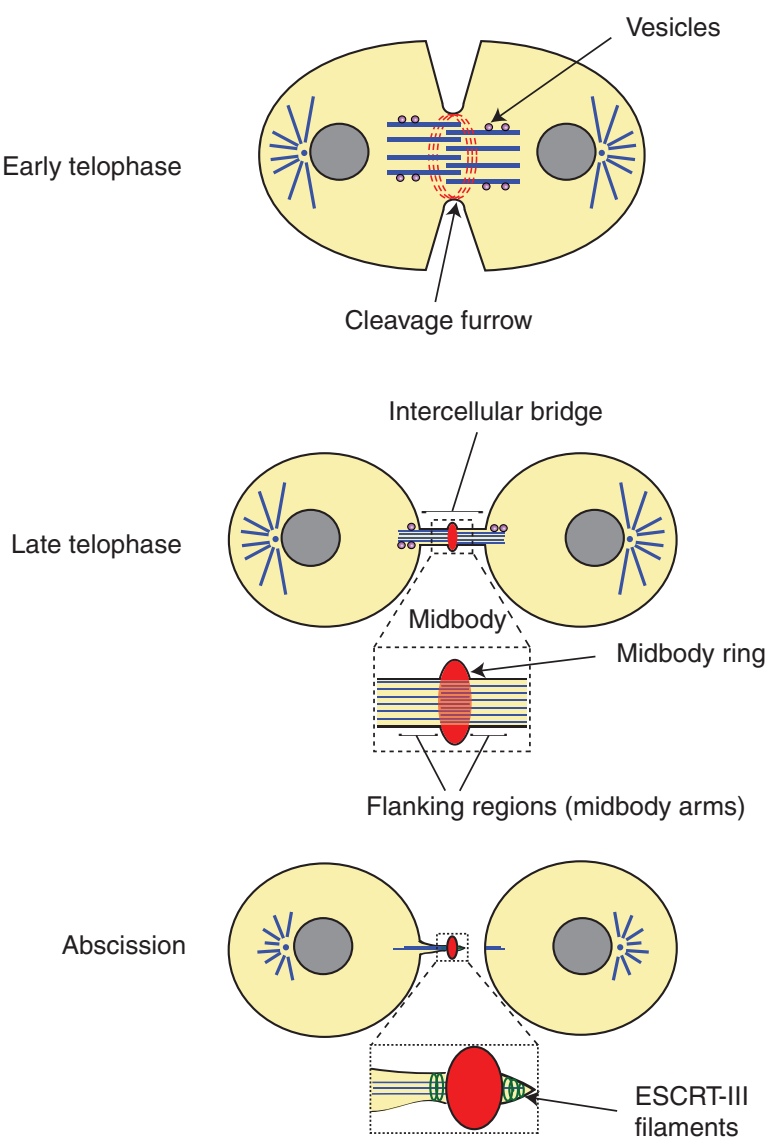

Figure 1. Schematic diagram illustrating the different stages of cytokinesis in animal cells. Microtubules are depicted in blue, the actomyosin contractile ring and the midbody ring in red, and the endosomal sorting complex required for transport (ESCRT)-III spiral filaments in green.

the two masses of segregating chromosomes. It became evident since the early findings by Rappaport (1961) that spindle microtubules were key to this process. The mitotic spindle is completely reorganized after anaphase onset into an array of interdigitating and antiparallel microtubules, known as the central spindle (Fig. 1). This structure originates, in large part, from the interpolar microtubules of the mitotic spindle that are released from centrosomes in anaphase and become tightly bundled at their plus ends in a region known as the spindle midzone 
(Fig. 1). However, de novo microtubule polymerization has also been proposed to play a role in central spindle formation (Douglas and Mishima 2010). Many cytoskeletal and signaling proteins cooperate to assemble and organize the central spindle. These include the chromosomal passenger complex (CPC), the microtubule-associated protein (MAP) protein regulator of cytokinesis 1 (PRC1), and at least three kinesin-like motors: KIF4A, KIF20A, and KIF23 (Table 1). PRC1 is a microtubule-bundling protein that is transported to the spindle midzone by KIF4A (Kurasawa et al. 2004; Zhu and Jiang 2005; Zhu et al. 2006). Cyclin-dependent kinase 1 (Cdk1) prevents the interaction between PRC1 and KIF4A before anaphase onset, which is instead later promoted by the enzymatic component of the CPC, Aurora B kinase (Zhu and Jiang 2005; Bastos et al. 2013). PRC1 is able to cross link microtubules, and KIF4A has been shown to suppress microtubule dynamics and control the size of the central spindle (Bieling et al. 2010; Subramanian et al. 2010; Hu et al. 2011; Bastos et al. 2013). KIF23 is also important for bundling central spindle microtubules as part of a protein complex, dubbed centralspindlin, whose other subunit is the Rho family GTPase-activating protein RacGAP1/MgcRacGAP (Mishima et al. 2002). Centralspindlin is a conserved heterotetramer composed of KIF23 and RacGAP1 dimers. It is essential for central spindle formation in many organisms and has been shown to be able to bundle microtubules in vitro (Adams et al. 1998; Mishima et al. 2002; D'Avino et al. 2006). Cdk1 phosphorylation inhibits the binding of KIF23 to microtubules in metaphase, whereas, after anaphase onset, KIF23 localization to the spindle midzone depends on the CPC, which also promotes the microtubule bundling activity of centralspind-

Table 1. List of the names used in different organisms for the factors involved in central spindle and contractile ring assembly/dynamics during cytokinesis

\begin{tabular}{llll}
\hline Mammals & Drosophila & \multicolumn{1}{c}{$\begin{array}{c}\text { Caenorhabditis } \\
\text { elegans }\end{array}$} & \multicolumn{1}{c}{ Function } \\
\hline Anillin & Anillin & ANI-1 & Contractile ring component \\
Aurora B & Aurora B & AIR-2 & Kinase (CPC component) \\
ASPM & Asp & ASPM-1 & MAP \\
Borealin & Borr & CSC-1 & CPC component \\
CIT-K & Sti/dCIT-K & Unknown & Kinase \\
CLASP & ORBIT/ & CLS-2 & MAP \\
& MAST & & \\
ECT-2 & Pbl & LET-21 & GEF \\
INCENP & INCENP & ICP-1 & CPC component \\
KIF4A & KLP3A & KLP-19 & KLP \\
KIF14 & Neb & KLP-6 & KLP \\
KIF18 & KLP67A & KLP-13 (?) & KLP \\
KIF20A (also known as & Sub & Unknown & KLP \\
$\quad$ MKLP2 and Rab6-KIFL) & & & \\
KIF23 (two isoforms, MKLP1 & Pav & ZEN-4 & KLP (centralspindlin \\
and CHO1) & & & component) \\
MgcRacGAP/RacGAP1 & RacGAP50C & CYK-4 & GAP (centralspindlin \\
Plk1 & & & component) \\
PRC1 & Polo & PLK-1 & Kinase \\
RhoA & Feo & SPD-1 & MAP \\
ROCK & Rho1 & RHO-1 & GTPase \\
\hline
\end{tabular}

CIT-K, citron kinase; CPC, chromosomal passenger complex; GAP, GTPase-activating protein; GEF, guanine nucleotide exchange factor; GTP, guanosine triphosphate; KLP, kinesin-like protein; MAP, microtubule-associated protein; Plk1, Pololike kinase 1; ROCK, Rho-associated kinase. The question mark (?) indicates that the relationship is unclear. 
P.P. D'Avino et al.

lin through Aurora B phosphorylation (Kaitna et al. 2000; Mishima et al. 2004; Guse et al. 2005). Finally, KIF20A is responsible for recruiting the CPC to the spindle midzone, thereby creating a pool of active Aurora B, which is essential for controlling the activity of KIF4A and KIF23 (Gruneberg et al. 2004; Fuller et al. 2008). In addition to these factors, other MAPs are likely to be involved in central spindle assembly and maintenance (Table 1), including the kinesin KIF14, which interacts with PRC1 (Gruneberg et al. 2006; Bassi et al. 2013), KIF18 (Gatt et al. 2005), CLIP-associating protein 1 (CLASP) (Inoue et al. 2004), and abnormal spindlelike microcephaly-associated protein (ASPM), which is the only MAP that localizes to the minus ends of central spindle microtubules (Wakefield et al. 2001; Riparbelli et al. 2002).

Several studies over $>50 \mathrm{yr}$ have indicated that both astral and central microtubules contribute to cleavage plane positioning and two distinct models were initially proposed (Glotzer 2004; D’Avino et al. 2005; von Dassow 2009). The "astral relaxation" model posited that astral microtubules could inhibit furrow formation at the polar regions, allowing constriction of the cortex only at the equator. In contrast, the "equatorial and central spindle stimulation" model proposed that a particular stable population of astral microtubules could contact the equatorial cortex and directly promote furrow ingression in cooperation with signals from the central spindle. It became obvious, however, that these two models were not mutually exclusive and the current view is that both mechanisms can coexist and the contribution of different populations of microtubules may vary in relation to the cell's shape and size. For example, in large embryonic cells (e.g., echinoderm and Caenorhabditis elegans embryos), containing prominent asters and small central spindles, astral microtubules could play a major role in positioning the cleavage plane and promoting furrow ingression. On the other end, in small epithelial cells, the equatorial and central spindle microtubules could play a more prominent role in these processes. Finally, there is also evidence that, in asymmetric divisions, additional cortical polarity-determining cues could co- operate with signals from the microtubules to position the cleavage plane (Cabernard et al. 2010). The spatial coupling of the cleavage plane to the mitotic spindle in animal cells facilitates the coordination of nuclear and cytoplasmic division, a prerequisite for cell reproduction.

\section{CLEAVAGE FURROW INGRESSION: ACTOMYOSIN FILAMENTS TAKE CENTER STAGE}

In many animal cells, actomyosin filaments assemble at the cleavage furrow, often forming an annular structure known as the "contractile ring” (Fig. 1). The contraction of these actomyosin filaments is currently seen as the major, although not the sole, driving force that triggers furrow ingression (Wang 2005). The small GTPase RhoA controls assembly and constriction of the contractile ring by activating two parallel signaling pathways (Piekny et al. 2005; Jordan and Canman 2012). On binding the diaphanous (Dia) members of formin-homology proteins, RhoA stimulates profilin-mediated actin polymerization (Fig. 2). Simultaneously, RhoA also activates Rho-associated kinase (ROCK), which phosphorylates the myosin regulatory light chain (MRLC), thereby promoting myosin contractility (Fig. 2). Therefore, the formation of an active zone of RhoA at the equatorial cortex is thought to be the key event that triggers cleavage furrow formation and ingression (Bement et al. 2005; D’Avino et al. 2005). How can microtubules generate such an active and focused RhoA zone? Like all GTPases, RhoA can exist in two states: an active, guanosine triphosphate (GTP)-bound form, and an inactive, GDP-bound form (Fig. 2). The flux between these two states is controlled by activators, known as guanine nucleotide exchange factors (GEFs), that accelerate the exchange of GDP for GTP and target Rho GTPases to the membrane, and inhibitors, GTPase-activating proteins (GAPs), that promote the intrinsic GTPase activity of Rho GTPases (Fig. 2). Astral microtubules have been described to be able to inhibit RhoA at the polar cortical regions and control actomyosin dynamics (Werner et al. 2007; Mur- 


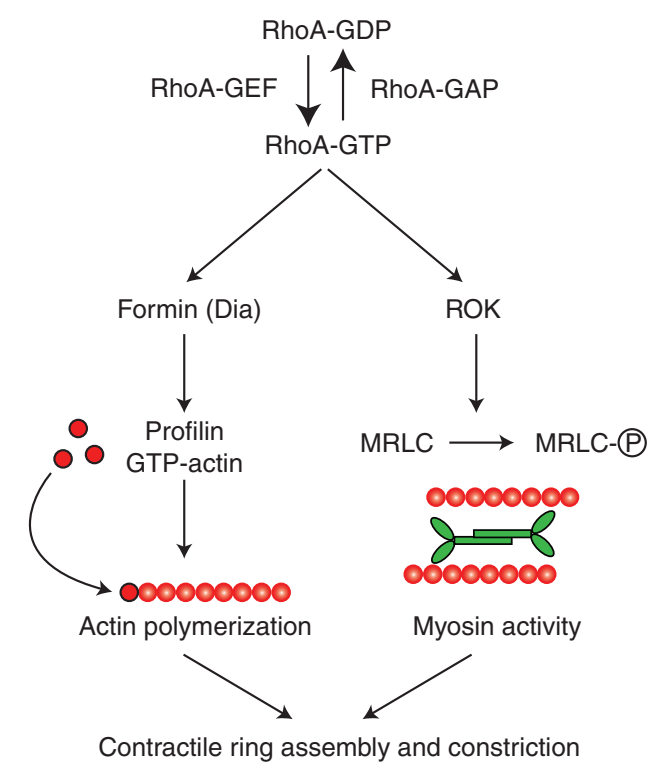

Figure 2. Schematic diagram of the RhoA-activated signaling pathways controlling actomyosin dynamics during cytokinesis. See text for details. Dia, diaphanous; GAP, GTPase-activating protein; GDP, guanosine diphosphate; GEF, guanine nucleotide exchange factor; GTP, guanosine-triphosphate; MRLC, myosin regulatory light chain; ROK, Rho kinase.

thy and Wadsworth 2008). The exact molecular mechanism, however, is still obscure, albeit it likely involves activation of a RhoA-specific GAP. In contrast, the mechanism by which equatorial and central spindle microtubules stimulate RhoA at the equatorial cortex is much better understood. The centralspindlin complex is able to travel to the plus ends of equatorial and central spindle microtubules thanks to the motor activity of its kinesin component KIF23 (Hutterer et al. 2009). The other component of the complex, MgcRacGAP/RacGAP1, interacts with the RhoGEF ECT2 (Somers and Saint 2003; Yuce et al. 2005). This interaction is necessary for ECT2 activation and transport to the equatorial cortex, where this GEF associates with the plasma membrane and activates RhoA, thereby triggering the signaling cascade responsible for the assembly and contraction of actomyosin filaments (Fig. 3) (Lee et al. 2004; Yuce et al. 2005; Zhao and Fang 2005; Kamijo et al. 2006; Su et al. 2011). The interaction between
ECT2 and RacGAP1 requires phosphorylation of RacGAP1 by Polo-like kinase 1 (Plk1) in anaphase/telophase and is, instead, inhibited by Cdk1-mediated phosphorylation of ECT2 in metaphase (Yuce et al. 2005; Burkard et al. 2007, 2009; Petronczki et al. 2007; Wolfe et al. 2009). Phosphorylation of the ECT2 carboxyterminal polybasic cluster region by Cdk1 also prevents the association of this GEF with the plasma membrane before anaphase onset ( $\mathrm{Su}$ et al. 2011).

The exact role of the GAP activity of RacGAP1 has been debated over the last decade. Initial evidence indicated that this GAP is significantly more active in vitro toward Rac, another member of the Rho family of GTPases, rather than RhoA (Toure et al. 1998; JantschPlunger et al. 2000). Subsequently, genetic studies in Drosophila and C. elegans also suggested that RacGAP1 could inactivate Rac GTPases in vivo (D'Avino et al. 2004; Canman et al. 2008), and this would inhibit the formation of a branched actomyosin web and, therefore, reduce stiffness at the equatorial cortex (Fig. 3) (D'Avino et al. 2005; Canman et al. 2008). Evidence in human cells also indicated that the GAP activity of RacGAP1 could be required to inhibit Rac-dependent pathways involved in cell adhesion and spreading (Fig. 3) (Bastos et al. 2012). Together, these findings suggest that the major role of RacGAP could be to down-regulate Rac GTPases at the cleavage site to reduce cortical stiffness and inhibit cell adhesion, thus, allowing robust and rapid furrow ingression. In contrast, a study in Xenopus embryos reported that the GAP domain of RacGAP1 could both transiently anchor RhoA and promote its inactivation at the division site, counteracting ECT2 and contributing to the flux of RhoA through the GTPase cycle (Fig. 3) (Miller and Bement 2009). However, similar findings have not been reported in other systems and at least two other GAPs, p190RhoGAP and ARHGAP11A, have also been reported to inhibit RhoA during cell division (Mikawa et al. 2008; Zanin et al. 2013). Therefore, it is currently unclear whether this role of RacGAP1 is conserved.

It is important for successful cytokinesis that the contractile ring is properly "scaffolded" 
P.P. D'Avino et al.

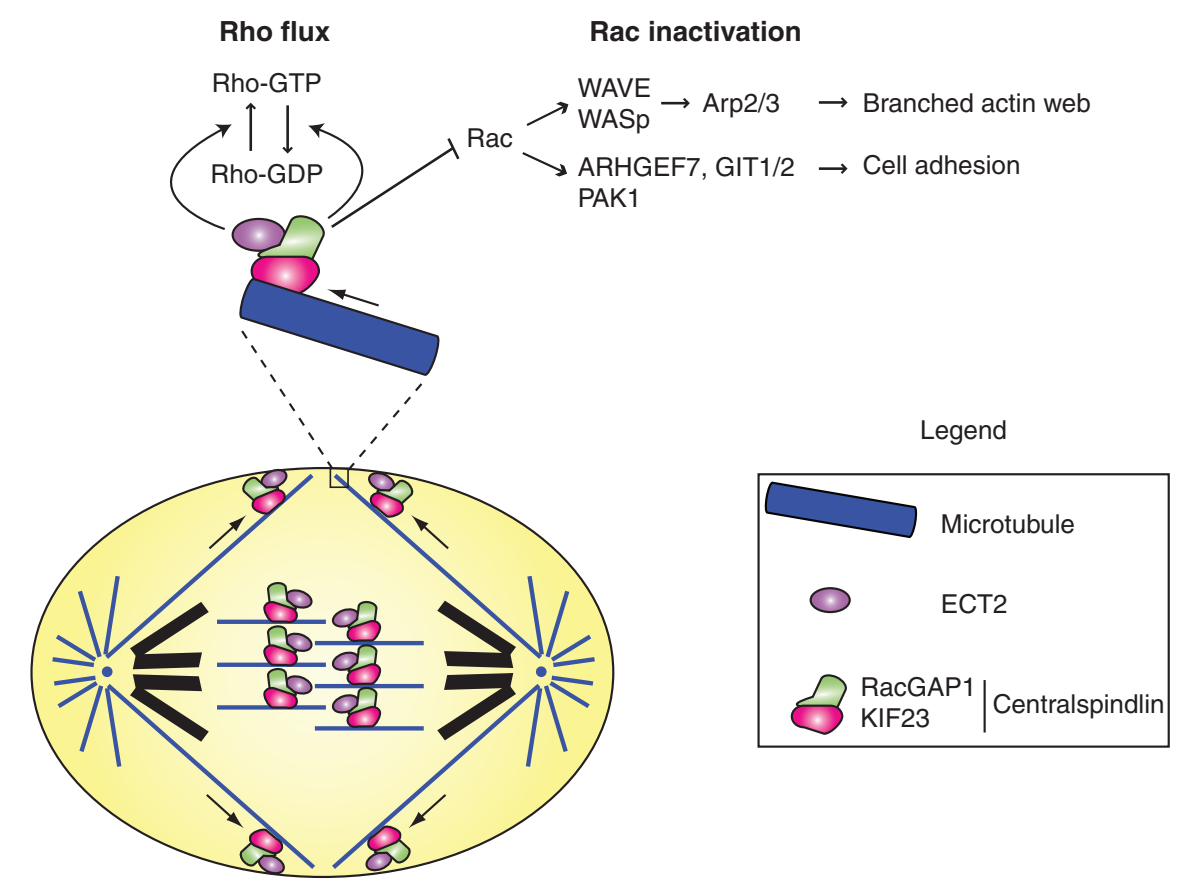

Figure 3. Model of RhoA regulation during cytokinesis. The centralspindlin complex binds to ECT2 and travels to the plus ends of both equatorial and central spindle microtubules. On reaching the cortex, ECT2 activates RhoA, which, in turn, promotes the assembly of the actomyosin ring (not depicted). The RacGAP component of centralspindlin inhibits Rac GTPase to reduce cortical stiffness and inhibit cell adhesion, thus, allowing robust and rapid furrow ingression. GAP, GTPase-activating protein; GDP, guanosine diphosphate; GTP, guanosine triphosphate.

and connected to both the cell membrane and central spindle. Two contractile ring proteins play this role: anillin and citron kinase (CIT$\mathrm{K})$. Both proteins associate with actin and myosin and interact directly with RhoA, although they do not seem to behave as canonical RhoA effectors (Madaule et al. 1995; Piekny and Glotzer 2008; D’Avino 2009; Bassi et al. 2011). In particular, CIT-K is required for proper RhoA localization, indicating that it behaves more like a RhoA regulator (Bassi et al. 2011; Gai et al. 2011). Moreover, this kinase has been reported to control the localization of a network comprising contractile ring components, anillin, actin, myosin, and RhoA, and at least three central spindle MAPs, KIF14, KIF23, and PRC1, important for the formation of an organelle, the midbody, that originates after completion of furrow ingression and regulates abscission (Fig. 1; see also the following paragraphs) (Bassi et al. 2013). Anillin links the plasma membrane with the contractile ring (Liu et al. 2012) and recruits the cytoskeletal proteins septins to the cleavage site (Field et al. 2005a). It also interacts with ECT2 and RacGAP1, but, unlike CIT-K, loss of anillin does not affect localization of its central spindle partners (D'Avino et al. 2008; Gregory et al. 2008; Frenette et al. 2012). This suggests that these interactions do not play a major structural role, but rather establish a platform necessary to maximize the efficiency of the signaling pathways required for cleavage furrow ingression. Consistent with the roles of anillin and CIT-K as stabilizers and linkers of the contractile ring, cells depleted of either of these two proteins show numerous cortical blebs at the cleavage site (Somma et al. 2002; D'Avino et al. 2004; Naim et al. 2004). However, individual inactivation of either anillin or CIT-K does not compromise cleavage furrow ingression, 
but after loss of anillin, the contractile ring can sometimes become unstable and oscillate laterally (Hickson and O’Farrell 2008; Piekny and Glotzer 2008). Interestingly, these oscillations increase after simultaneous loss of both anillin and CIT-K, indicating a possible functional redundancy between the two proteins (El Amine et al. 2013).

\section{MEMBRANE FORMATION AND COMPOSITION: DIRECTING TRAFFIC AND DELIVERY}

In addition to the force generated by actomyosin ring constriction, successful cytokinesis requires extensive membrane trafficking activities (McKay and Burgess 2011; Neto et al. 2011; Tang 2012). The massive increase in total surface area during furrowing requires the transport of membrane vesicles to be inserted at the cleavage site. Moreover, vesicle traffic to the furrow is associated with the timely delivery of regulatory proteins and remodeling factors required at different stages of this process (Neto et al. 2011).

Studies in mammalian cells and animal model systems have implicated several components of the secretory and endocytic/recycling machineries in cytokinesis (Prekeris and Gould 2008; Neto et al. 2011; Giansanti et al. 2012; Tang 2012). A proteomics-based analysis of purified midbodies isolated from Chinese hamster ovary cells revealed that the largest proportion of midbody proteins had a known role in secretory and membrane trafficking; the requirement for cytokinesis of many of the homologs was confirmed by RNA interference in C. elegans (Skop et al. 2004). The secretory pathway starts in the endoplasmic reticulum (ER), and comprises vesicle transport initially to the Golgi and then to the plasma membrane. The endocytic pathway begins, instead, with vesicle budding at the plasma membrane. Endocytosed vesicles are first routed to early endosomes and then return to recycling endosomes (REs), which directs them back to the plasma membrane (McKay and Burgess 2011). In human HeLa cells, secretory vesicles labeled with the fluorescently tagged secretory marker luminal-GFP (green fluorescent protein) were observed to move toward the cleavage site where they released their GFP signals, suggesting vesicle fusion with the furrow plasma membrane (Gromley et al. 2005). Transport of secretory vesicles to the cleavage furrow was also shown by later work of Goss and Toomre (2008), which provided evidence that Golgi-derived vesicles not only traffic to the furrow region from both daughter cells, but also dock and fuse there. Visualization of the dynamics of F-actin and endocytic vesicles in Drosophila embryos has led to a model, in which F-actin and vesicles are targeted as a unit to the cleavage furrow (Albertson et al. 2008).

Consistent with a role of secretory vesicle trafficking in furrowing, cytokinesis in both C. elegans embryos and Drosophila spermatocytes was shown to be sensitive to brefeldin A, a fungal metabolite that interferes with anterograde transport from ER to the Golgi (Skop et al. 2001; Robinett et al. 2009; Kitazawa et al. 2012). Moreover, both RNA interference (RNAi)-based and classical genetic screens in Drosophila have implicated Golgi-related functions in cytokinesis (Farkas et al. 2003; Echard et al. 2004; Eggert et al. 2004; Giansanti et al. 2004; Belloni et al. 2012; Kitazawa et al. 2012). Genetic dissection of cytokinesis in Drosophila spermatocytes indicated the requirement of important regulatory proteins of Golgi trafficking. These include the Golgi SNARE syntaxin 5 (Xu et al. 2002), the conserved oligomeric Golgi (COG) subunits Cog5 and Cog7 (Farkas et al. 2003; Belloni et al. 2012), and the ortholog of the yeast TRAPP II (trafficking transport protein particle II) TRS120p subunit (Robinett et al. 2009). Moreover, there is evidence for an involvement of retrograde transport from Golgi to ER in Drosophila cytokinesis. Two RNAi large screens in Drosophila S2 cells and a genetic screen in spermatocytes identified subunits of COPI, a coatomer protein complex consisting of seven proteins that regulates retrograde transport from the Golgi apparatus to the ER (Echard et al. 2004; Eggert et al. 2004; Robinett et al. 2009; Kitazawa et al. 2012).

Endocytic and recycling proteins are also key players in mediating both furrow ingression and abscission (Prekeris and Gould 2008). 
P.P. D'Avino et al.

Mutations in genes encoding endocytic components, such as clathrin and dynamin, were shown to disrupt cytokinesis in several animal models and mammalian cells (Wienke et al. 1999; Gerald et al. 2001; Thompson et al. 2002). Three small GTPases that regulate recycling trafficking, Rab11, Arf6, and Rab35, are required for completion of cytokinesis in a variety of cell types (Montagnac et al. 2008; Schiel and Prekeris 2013). Rab11, which mainly regulates the recycling of vesicles from REs to plasma membrane, was first found essential for furrow ingression in C. elegans (Skop et al. 2001). In Drosophila melanogaster, Rab11 provides an essential role for cytokinesis in S2 cells and spermatocytes (Kouranti et al. 2006; Giansanti et al. 2007) and for embryo cellularization (Pelissier et al. 2003; Riggs et al. 2003). In Drosophila spermatocytes, Rab11 localizes to the cleavage furrow together with its effector Nuclear fallout (Nuf) and is required for both furrow ingression and actin ring constriction, suggesting an intimate relationship between membrane addition and actomyosin remodeling during cytokinesis (Giansanti et al. 2007). In mammalian cells, both the Nuf ortholog FIP3/Arfophilin and Rab11 accumulate at the cleavage furrow and depletion of either protein by RNAi results in cytokinesis failures (Wilson et al. 2005). FIP3 and the other Rab11 effector, FIP4 (both sharing homology with Nuf), form a complex with Arf6 and depend on this protein for targeting to the central spindle (Fielding et al. 2005). Arf6 and FIP3/FIP4 also interact with Exo70, a subunit of the exocyst complex, a multiprotein complex that provides an essential role in tethering vesicles to plasma membrane before fusion (Prigent et al. 2003; Fielding et al. 2005). Consistent with a requirement for the exocyst complex in cytokinesis, knockdown of the exocyst subunit Sec5 results in the accumulation of v-SNARE-containing vesicles at the midbody in HeLa cells (Gromley et al. 2005). The Arf6/FIP3/FIP4 complex is not conserved in Drosophila. Nuf fails to bind to Arf6 and depends on Rab11 for its recruitment to the cell midzone (Hickson et al. 2003; Riggs et al. 2003; Giansanti et al. 2007). However, Arf6 is still required for furrow ingression in Drosophila spermatocytes, in which it acts downstream of Rab4/Rab11 endosomes (Dyer et al. 2007). Interestingly, Drosophila ARF6 binds to the centralspindlin component Pav (Table 1), suggesting that this association might contribute to Arf6 recruitment to central spindle endosomes (Dyer et al. 2007).

The small GTPase Rab35 is another important player in cytokinesis in both Drosophila and mammalian cultured cells (Kouranti et al. 2006). In human cells, Rab35 was found enriched at the plasma membrane and endocytic compartments, in which it regulates a fast endocytic recycling pathway during the terminal cytokinetic stages to ensure bridge stability and normal abscission (Kouranti et al. 2006).

A special lipid composition at the furrowing plasma membrane contributes to successful cytokinesis (Brill et al. 2011; Neto et al. 2011; Atilla-Gokcumen et al. 2014). For example, special lipids containing very long chain fatty acids are essential for cell shape deformation during cleavage furrow ingression (Szafer-Glusman et al. 2008). In addition, the interaction between specific lipid molecules and proteins forms signaling platforms, controlling several aspects of cytokinesis ( $\mathrm{Ng}$ et al. 2005; Neto et al. 2011). Phosphatidylinositol (PI) phosphates are critical membrane signals that control both actomyosin ring dynamics and membrane trafficking during cytokinesis (Brill et al. 2011). Consistent with this, the PI4-kinase Four-wheel drive (Fwd) and the PI(4)P binding protein GOLPH3 are both required for cytokinesis in Drosophila spermatocytes (Brill et al. 2000; Polevoy et al. 2009; Sechi et al. 2014). Some evidence also indicates that the phosphoinositide phosphatidylinositol 4,5-biphosphate (PI(4,5)P2) is enriched at the cleavage furrows of dividing tissue culture cells and Drosophila spermatocytes, in which it regulates formation and stability of the cytokinetic ring (Field et al. 2005b; Wong et al. 2005; Echard 2012). PI(4,5)P2 interacts with the contractile ring components anillin and septins and regulates F-actin polymerization by modulating the activity of the actin-binding proteins profilin and cofilin (Yin and Janmey 2003; Bertin et al. 2010; Liu et al. 2012). Finally, recent studies have shown that the RhoGEF ECT2 and the centralspindlin subunit MgcRacGAP con- 
tain protein domains that bind to polyanionic phosphoinositide lipids (Su et al. 2011; Frenette et al. 2012; Lekomtsev et al. 2012). Consistent with these observations, enrichment of $\mathrm{PI}(4,5)$ P2 is restricted to the cleavage furrow to maintain contractile ring structure (Ben El Kadhi et al. 2011). Knockdown of the PI(4,5)P2 phosphatase ORCL (oculocerebrorenal syndrome of Lowe) in Drosophila S2 cells leads to accumulation of contractile ring proteins on $\mathrm{PI}(4,5) \mathrm{P} 2$ containing endosomes. PI(4,5)P2 can also contribute to plasma membrane remodeling during cytokinesis through the recruitment of F-BAR proteins, a family of evolutionarily conserved proteins that facilitate membrane curvature (Brill et al. 2011; Takeda et al. 2013). The Drosophila F-BAR protein syndapin colocalizes with $\mathrm{PI}(4,5) \mathrm{P} 2$ to the cleavage site and directly interacts with anillin, thus, mediating a link between the plasma membrane and the contractile ring (Takeda et al. 2013). Accordingly, abnormal ex- pression of Syndapin affects cortical dynamics in cytokinesis (Takeda et al. 2013).

\section{MAKING THE FINAL CUT: THE MIDBODY MASTERS IT ALL}

The constriction of the contractile ring progressively compacts the central spindle to form an organelle, the midbody, which persists for a long time and provides a platform necessary for the proper recruitment and organization of many proteins that regulate the final abscission of the two daughter cells (Fig. 1). The midbody was first described by Flemming (1891) and then analyzed in detail by electron microscopy in the 20th century (Buck and Tisdale 1962a,b; Byers and Abramson 1968; Mullins and Biesele 1977). This organelle is composed by tight bundles of microtubules of an initial diameter of $\sim 1 \mu \mathrm{m}$ that contains, at its center, an amorphous electron-dense matrix (Fig. 4A). Various
A
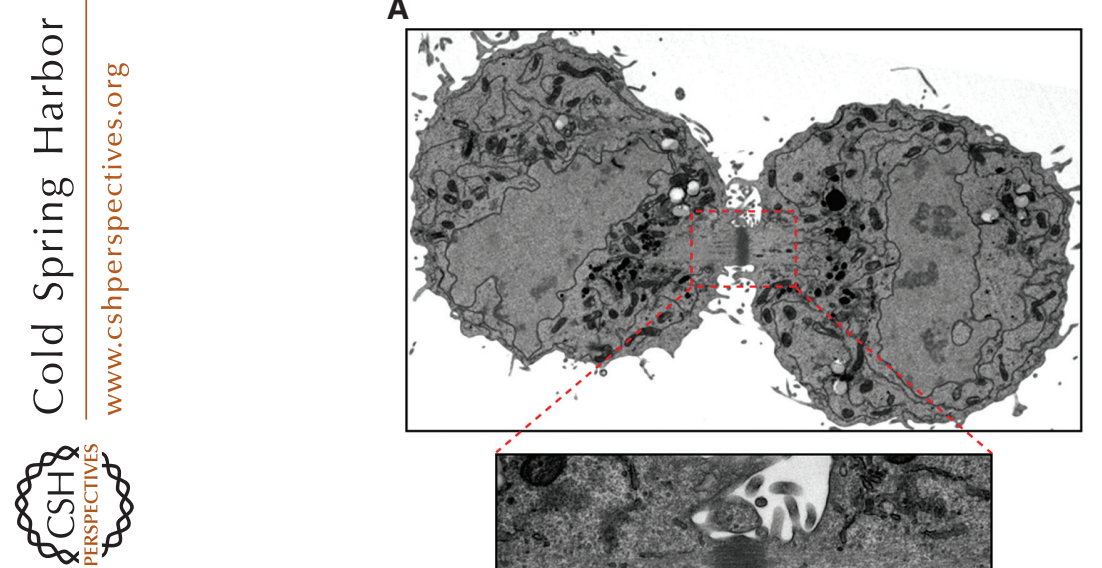

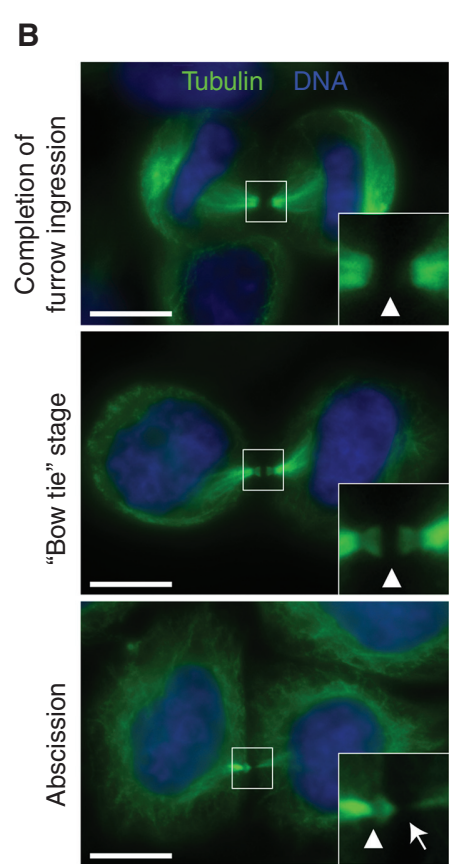

Figure 4. Midbody formation and structure in late cytokinesis. (A) Electron microscopy image of a HeLa cell in cytokinesis is shown at the top and at the bottom is a magnification of the midbody. MR, midbody ring. Scale bar, $1 \mu \mathrm{m}$. (B) Midbody stages in late cytokinesis. HeLa cells were fixed and stained to detect tubulin and DNA. Insets show a $3 \times$ magnification of the midbody. The arrowheads indicate the midbody rings, and the arrows specify the abscission site. Scale bar, $10 \mu \mathrm{m}$. 
P.P. D'Avino et al.

terms, over the years, have been used to describe the different regions of the midbody, generating some confusion. For clarity, here, we use the term "midbody ring" to describe the phase and electron-dense central region, and the term "midbody arms" to indicate the regions flanking the midbody ring; the two regions together form the entire midbody (Figs. 1 and 4). The midbody is not a static structure, but it undergoes a series of morphological changes during the late stages of cytokinesis. When furrow ingression is complete, the midbody ring appears like a "dark region" in cells immunostained for microtubules, most likely because the dense cluster of proteins that form the midbody ring prevent the access of antitubulin antibodies (Fig. 4B). After furrowing completion, two symmetric constrictions form at both sides of the midbody ring, making the midbody look like a "bow tie" (Fig. 4B). At this stage, the chromosomes are almost completely decondensed. Subsequently, the microtubule bundles become progressively thinner, an event most likely mediated by microtubule depolymerizing factors, such as katanin and spastin (Connell et al. 2009; Matsuo et al. 2013), and, ultimately, a distinct abscission site appears, usually first at one side of the midbody ring (Fig. 4B). The midbody remnant is, therefore, typically inherited by one of the two daughter cells and slowly eliminated by autophagy (Pohl and Jentsch 2009). However, the abscission event can vary in different cell types and the formation of two abscission sites at both sides of the midbody ring has also been described (Elia et al. 2011).

Both contractile ring and central spindle proteins contribute to midbody formation. Actomyosin filaments, however, disappear soon after completion of furrow ingression. Different midbody components display distinct spatial and temporal localization patterns. Some proteins, such as anillin, centralspindlin, CIT-K, and KIF14, localize to the midbody ring where they remain throughout the final stages of abscission and even persist in midbody remnants. In contrast, the CPC accumulates at the midbody arms and disappears after the "bow tie" stage. It is not completely clear, however, whether these different spatiotemporal localization patterns reflect distinct functions, albeit CPC removal from the midbody seems necessary to activate the molecular machinery that mediates abscission (see below). The roles that different midbody components play in the formation and stability of this organelle are not completely understood. Recent studies indicated that CIT-K is a key player in midbody formation. As mentioned previously, this contractile ring component links the actomyosin ring to the central spindle by interacting with contractile ring proteins, actin, myosin, anillin, and RhoA, and central spindle MAPs-KIF14, KIF23, and PRC1. Consistent with these molecular interactions, CIT-K is required for the recruitment of KIF14 to the cleavage site and proper distribution of actin, myosin, RhoA, KIF23, and PRC1 (Gruneberg et al. 2006; Bassi et al. 2011, 2013; Gai et al. 2011). In the absence of CIT-K, the midbody matrix is scarce, fragmented, detached from the cortex, and mispositioned in both Drosophila and human cells (Bassi et al. 2013; ZI Bassi and PP D'Avino, unpubl.). Anillin has been described to mediate the transition from contractile to midbody ring, although the molecular details are still missing (Kechad et al. 2012; El Amine et al. 2013). Anillin also accumulates at the lateral constrictions that generate the "bow tie" figures (Fig. 4B), and its interaction with septins has been proposed to be required for the formation of these constrictions (Renshaw et al. 2014). Finally, both anillin and the RacGAP component of centralspindlin have been shown to link directly the midbody ring to the plasma membrane (Kechad et al. 2012; Lekomtsev et al. 2012; Liu et al. 2012).

The mechanism that mediates membrane fission at the end of cytokinesis has remained obscure for a long time until it was reported that components of the endosomal sorting complex required for transport (ESCRT) localized to the midbody and were required for cytokinesis (Carlton and Martin-Serrano 2007; Morita et al. 2007). ESCRT proteins are highly conserved and best known for catalyzing membrane fission events both in virus budding and the sorting of receptors into vesicles that bud off into the lumen of the endosome, creating multivesicular bodies (MVBs) (McCullough et al. 2013). Four 
distinct ESCRTs, known as ESCRT-0, -I, -II, and -III, are sequentially recruited to endosomes and the final complex in the pathway, ESCRTIII, provides the core machinery that mediates membrane deformation and fission events during MVB biogenesis (Wollert et al. 2009). Cytokinesis is topologically similar to virus budding and MVB biogenesis and, thus, these findings indicated that the ESCRT machinery could also catalyze membrane fission during abscission. Consistent with this, the ESCRT-III Snf7 components (known as CHMP4 proteins in humans) have been observed to form spiral filaments that appear to remodel and constrict the membrane to create the abscission site (Fig. 1) (Elia et al. 2011; Guizetti et al. 2011). In human cells, ESCRT proteins are initially recruited to the midbody ring through direct interaction of Cep55 with the ESCRT-I component TSG101 and another MVB player, ALIX, which, in turn, recruits CHMP4 proteins (Carlton and Martin-Serrano 2007; Morita et al. 2007). Cep55, however, is not present in lower eukaryotes, such as Drosophila, and, therefore, this recruitment mechanism probably evolved in higher eukaryotes.

Finally, it is important to emphasize that abscission timing is precisely regulated by the CPC and Plk1. Plk1 phosphorylates Cep55 to prevent its interaction with KIF23 during furrow ingression (Bastos and Barr 2010). This ensures that Cep55 and, in turn, the ESCRT proteins accumulate at the midbody ring at a very late stage in cytokinesis. Furthermore, the CPC has been suggested to regulate abscission through the interaction of its subunit Borealin with all three ESCRT-III Snf7 components, CHMP4A, CHMP4B, and CHMP4C, and Aurora B phosphorylation of the carboxy-terminal tail of CHMP4C (Capalbo et al. 2012; Carlton et al. 2012), a region known to regulate CHMP4C's ability to polymerize and associate with membranes (Shim et al. 2007). The exact nature of this regulation, however, has been debated and two different models have been proposed. The model of Carlton et al. (2012) posits that Aurora B phosphorylation promotes CHMP4C translocation to the midbody ring, where this ESCRT-III component inhibits abscission. In contrast, Capalbo et al. (2012) proposed that the CPC could control the ability of CHMP4 proteins to assemble into the highly organized polymer arrays that catalyze membrane fission by using two concurrent mechanisms: interaction of its Borealin component with all three CHMP4 proteins and phosphorylation of CHMP4C by Aurora B. In this model, CHMP4 proteins could assemble into spiral filaments only after CPC removal from the midbody. This CPC-mediated regulation of ESCRT-III has been suggested to act as a checkpoint that prevents abscission in the presence of DNA at the cleavage site, thereby avoiding the formation of genetically abnormal daughter cells (Steigemann et al. 2009; Capalbo et al. 2012; Carlton et al. 2012).

\section{BAD BREAKUPS: CYTOKINESIS AND DISEASE}

The correct execution of cytokinesis is essential for the partitioning of replicated sister genomes and other cellular components, such as centrosomes, to daughter cells. Failure to undergo cytokinesis leads to the emergence of cells that carry a duplicated genome (tetraploidy) and supernumerary centrosomes (Ganem et al. 2007). Transplantation experiments in a mouse model have shown that tetraploid cells promote tumorigenesis (Fujiwara et al. 2005). Injection of tetraploid, but not genetically matched diploid cells, resulted in the growth of malignant mammary carcinomas. Tumors derived from tetraploid cells showed progressive structural and numerical chromosomal instability, a hallmark of the majority of solid human cancers. Although the reason for the occurrence of structural chromosome aberrations in tetraploid cells is not clear yet, the numerical aberrations (aneuploidy) detected in tetraploid cells are likely connected to the presence of supernumerary centrosomes that can interfere with spindle geometry and, hence, prevent accurate chromosome segregation (Ganem et al. 2009). Interestingly, recent multiregion analyses of human tumors identified genome duplication events at key branching points during the metastatic process (Gerlinger et al. 2012). This indicates 
P.P. D'Avino et al.

that tetraploidization through cytokinesis failure might promote adaptive evolution during tumor development. The implications of cytokinesis failure and genome duplication for the initiation, progression, and treatment of human malignancies requires further analyses.

Not only cytokinesis failure threatens genome integrity. Recent work in cultured human cells suggests that collisions between the ingressing cleavage furrow and segregating chromosomes can elicit DNA damage and chromosomal aberrations, such as translocations (Janssen et al. 2011). This finding underscores the importance of spatiotemporal coordination of chromosome segregation and cytokinesis. In addition to cancer, defects in cytokinesis and mutations in cytokinetic factors are also associated with other human diseases, such as Lowe syndrome, congenital anemia, and age-related macular degeneration (Lacroix and Maddox 2012). The successful execution of cytokinesis, thus, not only underlies the birth of new cells, but also protects us from genome instability, cancer, and other pathologies.

\section{CONCLUDING REMARKS AND FUTURE PERSPECTIVES}

Over the last decades, genetic screens and RNAibased approaches have led to the identification of an array of conserved regulators of cytokinesis in animal cells (see Table 1) (Glotzer 2005; Eggert et al. 2006; Fededa and Gerlich 2012; Green et al. 2012). It is likely that few nonredundant, conserved, and critical regulators of cytokinesis remain to be discovered. Equipped with the knowledge of most of the proteins involved, one of the goals of future work is to define the mechanistic basis for the execution of cytokinesis. Breakthroughs in this area are likely to require the combination of biophysical, super resolution, computational, and optogenetic approaches with the more traditional avenues of genetics, cell biology, and biochemistry. Key questions and areas to be addressed by future research include: (1) How does the mitotic spindle break cortical isotropy to focus contractility in the equatorial region during cleavage plane specification? What is the molecular basis for polar relaxation induced by astral microtubules and for the induction of contractility by equatorial microtubules? (2) Following cleavage plane specification, the contractile ring assembles to drive ingression of the cytokinetic furrow. It is currently not know whether local accumulation of RhoA-GTP is sufficient to induce furrowing. Recent advances have paved the way for studying contractile ring action in a partially purified system in yeast (Mishra et al. 2013; Stachowiak et al. 2014). It will be exciting to define the biophysical basis for contractile ring dynamics and closure in animal cells. (3) Emerging evidence suggests that ESCRT-III complexes mediate abscission in mammalian cells. Reconstitution experiments in vitro, super resolution imaging in vivo, and computational modeling will be instrumental to defining the mechanism underlying the final cut during cytokinetic abscission (Elia et al. 2013). (4) Much of the work on cytokinetic mechanisms in mammals has focused on the analysis of cultured cells grown on artificial surfaces. Recent work in Drosophila has highlighted the importance of extrinsic forces and neighboring cells for cytokinesis in epithelial layers (Founounou et al. 2013; Guillot and Lecuit 2013; Herszterg et al. 2013; Moraisde-Sa and Sunkel 2013). In the future, it will be exciting to expand cytokinesis research also to mammalian multicellular systems or models. This list of questions and perspectives is by no means comprehensive and, to a certain extent, is subjective. The field of cytokinesis research still provides a plethora of exciting questions that need addressing by budding and senior scientists if we want to understand how daughter cells are born.

\section{ACKNOWLEDGMENTS}

We thank Z. Bassi for help with Figure 1, and L. Capalbo for one of the images in Figure 4B and critical reading of the manuscript. We apologize to all those colleagues whose work could not be discussed and/or cited because of length limitations. Research in the laboratory of P.P.D. is supported by Cancer Research UK and by the Maplethorpe Fellowship of Murray Edwards College, Cambridge, UK. Work in M.G.G.'s lab- 
oratory is supported by a grant from Associazione Italiana per la Ricerca sul Cancro (AIRC) (IG14671). Work in the laboratory of M.P. is supported by Cancer Research UK and the EMBO Young Investigator Programme.

\section{REFERENCES}

Adams RR, Tavares AA, Salzberg A, Bellen HJ, Glover DM 1998. Pavarotti encodes a kinesin-like protein required to organize the central spindle and contractile ring for $\mathrm{cy}$ tokinesis. Genes Dev 12: 1483-1494.

Albertson R, Cao J, Hsieh TS, Sullivan W. 2008. Vesicles and actin are targeted to the cleavage furrow via furrow microtubules and the central spindle. J Cell Biol 181: 777790.

Atilla-Gokcumen GE, Muro E, Relat-Goberna J, Sasse S, Bedigian A, Coughlin ML, Garcia-Manyes S, Eggert US. 2014. Dividing cells regulate their lipid composition and localization. Cell 156: 428-439.

Bassi ZI, Verbrugghe KJ, Capalbo L, Gregory S, Montembault E, Glover DM, D'Avino PP. 2011. Sticky/Citron kinase maintains proper RhoA localization at the cleavage site during cytokinesis. J Cell Biol 195: 595-603.

Bassi ZI, Audusseau M, Riparbelli MG, Callaini G, D’Avino PP. 2013. Citron kinase controls a molecular network required for midbody formation in cytokinesis. Proc Natl Acad Sci 110: 9782-9787.

Bastos RN, Barr FA. 2010. Plk1 negatively regulates Cep55 recruitment to the midbody to ensure orderly abscission. J Cell Biol 191: 751-760.

Bastos RN, Penate X, Bates M, Hammond D, Barr FA. 2012. CYK4 inhibits Rac1-dependent PAK1 and ARHGEF7 effector pathways during cytokinesis. J Cell Biol 198: 865880.

Bastos RN, Gandhi SR, Baron RD, Gruneberg U, Nigg EA, Barr FA. 2013. Aurora B suppresses microtubule dynamics and limits central spindle size by locally activating KIF4A. J Cell Biol 202: 605-621.

Belloni G, Sechi S, Riparbelli MG, Fuller MT, Callaini G, Giansanti MG. 2012. Mutations in Cog7 affect Golgi structure, meiotic cytokinesis and sperm development during Drosophila spermatogenesis. J Cell Sci 125: 54415452.

Bement WM, Benink HA, von Dassow G. 2005. A microtubule-dependent zone of active RhoA during cleavage plane specification. J Cell Biol 170: 91-101.

Ben El Kadhi K, Roubinet C, Solinet S, Emery G, Carreno S. 2011. The inositol 5-phosphatase dOCRL controls $\mathrm{PI}(4,5) \mathrm{P} 2$ homeostasis and is necessary for cytokinesis. Curr Biol 21: 1074-1079.

Bertin A, McMurray MA, Thai L, Garcia G 3rd, Votin V, Grob P, Allyn T, Thorner J, Nogales E. 2010. Phosphatidylinositol-4,5-bisphosphate promotes budding yeast septin filament assembly and organization. J Mol Biol 404: 711-731.

Bieling P, Telley IA, Surrey T. 2010. A minimal midzone protein module controls formation and length of antiparallel microtubule overlaps. Cell 142: 420-432.
Brill JA, Hime GR, Scharer-Schuksz M, Fuller MT. 2000. A phospholipid kinase regulates actin organization and intercellular bridge formation during germline cytokinesis. Development 127: 3855-3864.

Brill JA, Wong R, Wilde A. 2011. Phosphoinositide function in cytokinesis. Curr Biol 21: R930-R934.

Buck RC, Tisdale JM. 1962a. An electron microscopic study of the cleavage furrow in mammalian cells. J Cell Biol 13: $117-125$.

Buck RC, Tisdale JM. 1962b. The fine structure of the midbody of the rat erythroblast. J Cell Biol 13: 109-115.

Burkard ME, Randall CL, Larochelle S, Zhang C, Shokat KM, Fisher RP, Jallepalli PV. 2007. Chemical genetics reveals the requirement for Polo-like kinase 1 activity in positioning RhoA and triggering cytokinesis in human cells. Proc Natl Acad Sci 104: 4383-4388.

Burkard ME, Maciejowski J, Rodriguez-Bravo V, Repka M, Lowery DM, Clauser KR, Zhang C, Shokat KM, Carr SA, Yaffe MB, et al. 2009. Plk1 self-organization and priming phosphorylation of HsCYK-4 at the spindle midzone regulate the onset of division in human cells. PLoS Biol 7: e1000111.

Byers B, Abramson DH. 1968. Cytokinesis in HeLa: Posttelophase delay and microtubule-associated motility. Protoplasma 66: 413-435.

Cabernard C, Prehoda KE, Doe CQ. 2010. A spindle-independent cleavage furrow positioning pathway. Nature 467: 91-94.

Canman JC, Lewellyn L, Laband K, Smerdon SJ, Desai A, Bowerman B, Oegema K. 2008. Inhibition of Rac by the GAP activity of centralspindlin is essential for cytokinesis. Science 322: 1543-1546.

Capalbo L, Montembault E, Takeda T, Bassi ZI, Glover DM, D'Avino PP. 2012. The chromosomal passenger complex controls the function of endosomal sorting complex required for transport-III Snf7 proteins during cytokinesis. Open Biol 2: 120070.

Carlton JG, Martin-Serrano J. 2007. Parallels between cytokinesis and retroviral budding: A role for the ESCRT machinery. Science 316: 1908-1912.

Carlton JG, Caballe A, Agromayor M, Kloc M, Martin-Serrano J. 2012. ESCRT-III governs the Aurora B-mediated abscission checkpoint through CHMP4C. Science 336: $220-225$.

Connell JW, Lindon C, Luzio JP, Reid E. 2009. Spastin couples microtubule severing to membrane traffic in completion of cytokinesis and secretion. Traffic 10: 42-56.

D'Avino PP. 2009. How to scaffold the contractile ring for a safe cytokinesis-Lessons from Anillin-related proteins. J Cell Sci 122: 1071-1079.

D’Avino PP, Savoian MS, Glover DM. 2004. Mutations in sticky lead to defective organization of the contractile ring during cytokinesis and are enhanced by Rho and suppressed by Rac. J Cell Biol 166: 61-71.

D’Avino PP, Savoian MS, Glover DM. 2005. Cleavage furrow formation and ingression during animal cytokinesis: A microtubule legacy. J Cell Sci 118: 1549-1558.

D’Avino PP, Savoian MS, Capalbo L, Glover DM. 2006. RacGAP50C is sufficient to signal cleavage furrow formation during cytokinesis. J Cell Sci 119: 4402-4408. 
P.P. D'Avino et al.

D’Avino PP, Takeda T, Capalbo L, Zhang W, Lilley K, Laue E, Glover DM. 2008. Interaction between Anillin and RacGAP50C connects the actomyosin contractile ring with spindle microtubules at the cell division site. J Cell Sci 121: 1151-1158.

Douglas ME, Mishima M. 2010. Still entangled: Assembly of the central spindle by multiple microtubule modulators. Semin Cell Dev Biol 21: 899-908.

Dyer N, Rebollo E, Dominguez P, Elkhatib N, Chavrier P, Daviet L, Gonzalez C, Gonzalez-Gaitan M. 2007. Spermatocyte cytokinesis requires rapid membrane addition mediated by ARF6 on central spindle recycling endosomes. Development 134: 4437-4447.

Echard A. 2012. Phosphoinositides and cytokinesis: The "PIP" of the iceberg. Cytoskeleton 69: 893-912.

Echard A, Hickson GR, Foley E, O'Farrell PH. 2004. Terminal cytokinesis events uncovered after an RNAi screen. Curr Biol 14: 1685-1693.

Eggert US, Kiger AA, Richter C, Perlman ZE, Perrimon N, Mitchison TJ, Field CM. 2004. Parallel chemical genetic and genome-wide RNAi screens identify cytokinesis inhibitors and targets. PLoS Biol 2: e379.

Eggert US, Mitchison TJ, Field CM. 2006. Animal cytokinesis: From parts list to mechanisms. Annu Rev Biochem 75: $543-566$.

El Amine N, Kechad A, Jananji S, Hickson GR. 2013. Opposing actions of septins and Sticky on Anillin promote the transition from contractile to midbody ring. $J$ Cell Biol 203: 487-504.

Elia N, Sougrat R, Spurlin TA, Hurley JH, LippincottSchwartz J. 2011. Dynamics of endosomal sorting complex required for transport (ESCRT) machinery during cytokinesis and its role in abscission. Proc Natl Acad Sci 108: $4846-4851$.

Elia N, Ott C, Lippincott-Schwartz J. 2013. Incisive imaging and computation for cellular mysteries: Lessons from abscission. Cell 155: 1220-1231.

Farkas RM, Giansanti MG, Gatti M, Fuller MT. 2003. The Drosophila $\operatorname{Cog} 5$ homologue is required for cytokinesis, cell elongation, and assembly of specialized Golgi architecture during spermatogenesis. Mol Biol Cell 14: 190-200.

Fededa JP, Gerlich DW. 2012. Molecular control of animal cell cytokinesis. Nat Cell Biol 14: 440-447.

Field CM, Coughlin M, Doberstein S, Marty T, Sullivan W. 2005a. Characterization of anillin mutants reveals essential roles in septin localization and plasma membrane integrity. Development 132: 2849-2860.

Field SJ, Madson N, Kerr ML, Galbraith KA, Kennedy CE, Tahiliani M, Wilkins A, Cantley LC. 2005b. PtdIns(4,5)P2 functions at the cleavage furrow during cytokinesis. Curr Biol 15: 1407-1412.

Fielding AB, Schonteich E, Matheson J, Wilson G, Yu X, Hickson GR, Srivastava S, Baldwin SA, Prekeris R, Gould GW. 2005. Rab11-FIP3 and FIP4 interact with Arf6 and the exocyst to control membrane traffic in cytokinesis. EMBO J 24: 3389-3399.

Flemming W. 1891. Neue Beiträge zur Kenntnis der Zelle [Novel contributions to knowledge about the cell]. Arch Mikrosk Anat 37: 685-751.

Founounou N, Loyer N, Le Borgne R. 2013. Septins regulate the contractility of the actomyosin ring to enable adhe- rens junction remodeling during cytokinesis of epithelial cells. Dev Cell 24: 242-255.

Frenette P, Haines E, Loloyan M, Kinal M, Pakarian P, Piekny A. 2012. An anillin-Ect2 complex stabilizes central spindle microtubules at the cortex during cytokinesis. PLoS ONE 7: e34888.

Fujiwara T, Bandi M, Nitta M, Ivanova EV, Bronson RT, Pellman D. 2005. Cytokinesis failure generating tetraploids promotes tumorigenesis in p53-null cells. Nature 437: 1043-1047.

Fuller BG, Lampson MA, Foley EA, Rosasco-Nitcher S, Le KV, Tobelmann P, Brautigan DL, Stukenberg PT, Kapoor TM. 2008. Midzone activation of aurora B in anaphase produces an intracellular phosphorylation gradient. Nature 453: 1132-1136.

Gai M, Camera P, Dema A, Bianchi F, Berto G, Scarpa E, Germena G, Di Cunto F. 2011. Citron kinase controls abscission through RhoA and anillin. Mol Biol Cell 22: 3768-3778.

Ganem NJ, Storchova Z, Pellman D. 2007. Tetraploidy, aneuploidy and cancer. Curr Opin Genet Dev 17: 157-162.

Ganem NJ, Godinho SA, Pellman D. 2009. A mechanism linking extra centrosomes to chromosomal instability. Nature 460: 278-282.

Gatt MK, Savoian MS, Riparbelli MG, Massarelli C, Callaini G, Glover DM. 2005. Klp67A is a pre-anaphase microtubule catastrophe factor that is subsequently required for stable central spindle formation. J Cell Sci 118: 26712682.

Gerald NJ, Damer CK, O'Halloran TJ, De Lozanne A. 2001. Cytokinesis failure in clathrin-minus cells is caused by cleavage furrow instability. Cell Motil Cytoskeleton 48: 213-223.

Gerlinger M, Rowan AJ, Horswell S, Larkin J, Endesfelder D, Gronroos E, Martinez P, Matthews N, Stewart A, Tarpey P, et al. 2012. Intratumor heterogeneity and branched evolution revealed by multiregion sequencing. $N$ Engl J Med 366: $883-892$.

Giansanti MG, Farkas RM, Bonaccorsi S, Lindsley DL, Wakimoto BT, Fuller MT, Gatti M. 2004. Genetic dissection of meiotic cytokinesis in Drosophila males. Mol Biol Cell 15: 2509-2522.

Giansanti MG, Belloni G, Gatti M. 2007. Rab11 is required for membrane trafficking and actomyosin ring constriction in meiotic cytokinesis of Drosophila males. Mol Biol Cell 18: 5034-5047.

Giansanti MG, Sechi S, Frappaolo A, Belloni G, Piergentili R. 2012. Cytokinesis in Drosophila male meiosis. Spermatogenesis 2: 185-196.

Glotzer M. 2004. Cleavage furrow positioning. J Cell Biol 164: $347-351$.

Glotzer M. 2005. The molecular requirements for cytokinesis. Science 307: 1735-1739.

Goss JW, Toomre DK. 2008. Both daughter cells traffic and exocytose membrane at the cleavage furrow during mammalian cytokinesis. J Cell Biol 181: 1047-1054.

Green RA, Paluch E, Oegema K. 2012. Cytokinesis in animal cells. Annu Rev Cell Dev Biol 28: 29-58.

Gregory SL, Ebrahimi S, Milverton J, Jones WM, Bejsovec A, Saint R. 2008. Cell division requires a direct link between 
microtubule-bound RacGAP and Anillin in the contractile ring. Curr Biol 18: 25-29.

Gromley A, Yeaman C, Rosa J, Redick S, Chen CT, Mirabelle S, Guha M, Sillibourne J, Doxsey SJ. 2005. Centriolin anchoring of exocyst and SNARE complexes at the midbody is required for secretory-vesicle-mediated abscission. Cell 123: 75-87.

Gruneberg U, Neef R, Honda R, Nigg EA, Barr FA. 2004. Relocation of Aurora B from centromeres to the central spindle at the metaphase to anaphase transition requires MKlp2. J Cell Biol 166: 167-172.

Gruneberg U, Neef R, Li X, Chan EH, Chalamalasetty RB, Nigg EA, Barr FA. 2006. KIF14 and citron kinase act together to promote efficient cytokinesis. J Cell Biol 172: $363-372$.

Guillot C, Lecuit T. 2013. Adhesion disengagement uncouples intrinsic and extrinsic forces to drive cytokinesis in epithelial tissues. Dev Cell 24: 227-241.

Guizetti J, Schermelleh L, Mantler J, Maar S, Poser I, Leonhardt H, Muller-Reichert T, Gerlich DW. 2011. Cortical constriction during abscission involves helices of ESCRTIII-dependent filaments. Science 331: 1616-1620.

Guse A, Mishima M, Glotzer M. 2005. Phosphorylation of ZEN-4/MKLP1 by aurora B regulates completion of cytokinesis. Curr Biol 15: 778-786.

Herszterg S, Leibfried A, Bosveld F, Martin C, Bellaiche Y. 2013. Interplay between the dividing cell and its neighbors regulates adherens junction formation during cytokinesis in epithelial tissue. Dev Cell 24: 256-270.

Hickson GR, O'Farrell PH. 2008. Rho-dependent control of anillin behavior during cytokinesis. J Cell Biol 180: 285294.

Hickson GR, Matheson J, Riggs B, Maier VH, Fielding AB, Prekeris R, Sullivan W, Barr FA, Gould GW. 2003. Arfophilins are dual Arf/Rab 11 binding proteins that regulate recycling endosome distribution and are related to Drosophila nuclear fallout. Mol Biol Cell 14: 2908-2920.

Hu CK, Coughlin M, Field CM, Mitchison TJ. 2011. KIF4 regulates midzone length during cytokinesis. Curr Biol 21: $815-824$.

Hutterer A, Glotzer M, Mishima M. 2009. Clustering of centralspindlin is essential for its accumulation to the central spindle and the midbody. Curr Biol 19: 20432049.

Inoue YH, Savoian MS, Suzuki T, Mathe E, Yamamoto MT, Glover DM. 2004. Mutations in orbit/mast reveal that the central spindle is comprised of two microtubule populations, those that initiate cleavage and those that propagate furrow ingression. J Cell Biol 166: 49-60.

Janssen A, van der Burg M, Szuhai K, Kops GJ, Medema RH. 2011. Chromosome segregation errors as a cause of DNA damage and structural chromosome aberrations. Science 333: 1895-1898.

Jantsch-Plunger V, Gonczy P, Romano A, Schnabel H, Hamill D, Schnabel R, Hyman AA, Glotzer M. 2000. CYK-4: A Rho family GTPase activating protein (GAP) required for central spindle formation and cytokinesis. J Cell Biol 149: 1391-1404.

Jordan SN, Canman JC. 2012. Rho GTPases in animal cell cytokinesis: An occupation by the one percent. Cytoskeleton 69: 919-930.
Kaitna S, Mendoza M, Jantsch-Plunger V, Glotzer M. 2000. Incenp and an aurora-like kinase form a complex essential for chromosome segregation and efficient completion of cytokinesis. Curr Biol 10: 1172-1181.

Kamijo K, Ohara N, Abe M, Uchimura T, Hosoya H, Lee JS, Miki T. 2006. Dissecting the role of Rho-mediated signaling in contractile ring formation. Mol Biol Cell 17: 4355 .

Kechad A, Jananji S, Ruella Y, Hickson GR. 2012. Anillin acts as a bifunctional linker coordinating midbody ring biogenesis during cytokinesis. Curr Biol 22: 197-203.

Kitazawa D, Yamaguchi M, Mori H, Inoue YH. 2012. COPImediated membrane trafficking is required for cytokinesis in Drosophila male meiotic divisions. J Cell Sci 125: 3649-3660.

Kouranti I, Sachse M, Arouche N, Goud B, Echard A. 2006. Rab35 regulates an endocytic recycling pathway essential for the terminal steps of cytokinesis. Curr Biol 16: 17191725.

Kurasawa Y, Earnshaw WC, Mochizuki Y, Dohmae N, Todokoro K. 2004. Essential roles of KIF4 and its binding partner PRC1 in organized central spindle midzone formation. EMBO J 23: 3237-3248.

Lacroix B, Maddox AS. 2012. Cytokinesis, ploidy and aneuploidy. J Pathol 226: 338-351.

Lee JS, Kamijo K, Ohara N, Kitamura T, Miki T. 2004. MgcRacGAP regulates cortical activity through RhoA during cytokinesis. Exp Cell Res 293: 275-282.

Lekomtsev S, Su KC, Pye VE, Blight K, Sundaramoorthy S, Takaki T, Collinson LM, Cherepanov P, Divecha N, Petronczki M. 2012. Centralspindlin links the mitotic spindle to the plasma membrane during cytokinesis. Nature 492: $276-279$.

Liu J, Fairn GD, Ceccarelli DF, Sicheri F, Wilde A. 2012. Cleavage furrow organization requires $\mathrm{PIP}_{2}$-mediated recruitment of anillin. Curr Biol 22: 64-69.

Madaule P, Furuyashiki T, Reid T, Ishizaki T, Watanabe G, Morii N, Narumiya S. 1995. A novel partner for the GTPbound forms of rho and rac. FEBS Lett 377: 243-248.

Matsuo M, Shimodaira T, Kasama T, Hata Y, Echigo A, Okabe M, Arai K, Makino Y, Niwa S, Saya H, et al. 2013. Katanin p60 contributes to microtubule instability around the midbody and facilitates cytokinesis in rat cells. PLoS ONE 8: e80392.

McCullough J, Colf LA, Sundquist WI. 2013. Membrane fission reactions of the mammalian ESCRT pathway. Annu Rev Biochem 82: 663-692.

McKay HF, Burgess DR. 2011. "Life is a highway": Membrane trafficking during cytokinesis. Traffic 12: 247-251.

Mikawa M, Su L, Parsons SJ. 2008. Opposing roles of p190RhoGAP and Ect2 RhoGEF in regulating cytokinesis. Cell Cycle 7: 2003-2012.

Miller AL, Bement WM. 2009. Regulation of cytokinesis by Rho GTPase flux. Nat Cell Biol 11: 71-77.

Mishima M, Kaitna S, Glotzer M. 2002. Central spindle assembly and cytokinesis require a kinesin-like protein/ RhoGAP complex with microtubule bundling activity. Dev Cell 2: 41-54.

Mishima M, Pavicic V, Gruneberg U, Nigg EA, Glotzer M. 2004. Cell cycle regulation of central spindle assembly. Nature 430: 908-913. 
P.P. D'Avino et al.

Mishra M, Kashiwazaki J, Takagi T, Srinivasan R, Huang Y, Balasubramanian MK, Mabuchi I. 2013. In vitro contraction of cytokinetic ring depends on myosin II but not on actin dynamics. Nat Cell Biol 15: 853-859.

Montagnac G, Echard A, Chavrier P. 2008. Endocytic traffic in animal cell cytokinesis. Curr Opin Cell Biol 20: 454461.

Morais-de-Sa E, Sunkel C. 2013. Adherens junctions determine the apical position of the midbody during follicular epithelial cell division. EMBO Rep 14: 696-703.

Morita E, Sandrin V, Chung HY, Morham SG, Gygi SP, Rodesch CK, Sundquist WI. 2007. Human ESCRT and ALIX proteins interact with proteins of the midbody and function in cytokinesis. EMBO J 26: 4215-4227.

Mullins JM, Biesele JJ. 1977. Terminal phase of cytokinesis in D-98s cells. J Cell Biol 73: 672-684.

Murthy K, Wadsworth P. 2008. Dual role for microtubules in regulating cortical contractility during cytokinesis. J Cell Sci 121: 2350-2359.

Naim V, Imarisio S, Di Cunto F, Gatti M, Bonaccorsi S. 2004. Drosophila citron kinase is required for the final steps of cytokinesis. Mol Biol Cell 15: 5053-5063.

Neto H, Collins LL, Gould GW. 2011. Vesicle trafficking and membrane remodelling in cytokinesis. Biochem J 437: 13-24.

Ng MM, Chang F, Burgess DR. 2005. Movement of membrane domains and requirement of membrane signaling molecules for cytokinesis. Dev Cell 9: 781-790.

Pelissier A, Chauvin JP, Lecuit T. 2003. Trafficking through Rab11 endosomes is required for cellularization during Drosophila embryogenesis. Curr Biol 13: 1848-1857.

Petronczki M, Glotzer M, Kraut N, Peters JM. 2007. Pololike kinase 1 triggers the initiation of cytokinesis in human cells by promoting recruitment of the RhoGEF Ect2 to the central spindle. Dev Cell 12: 713-725.

Piekny AJ, Glotzer M. 2008. Anillin is a scaffold protein that links RhoA, actin, and myosin during cytokinesis. Curr Biol 18: 30-36.

Piekny A, Werner M, Glotzer M. 2005. Cytokinesis: Welcome to the Rho zone. Trends Cell Biol 15: 651-658.

Pohl C, Jentsch S. 2009. Midbody ring disposal by autophagy is a post-abscission event of cytokinesis. Nat Cell Biol 11: $65-70$.

Polevoy G, Wei HC, Wong R, Szentpetery Z, Kim YJ, Goldbach P, Steinbach SK, Balla T, Brill JA. 2009. Dual roles for the Drosophila PI 4-kinase four wheel drive in localizing Rab11 during cytokinesis. J Cell Biol 187: 847-858.

Prekeris R, Gould GW. 2008. Breaking up is hard to doMembrane traffic in cytokinesis. J Cell Sci 121: 15691576.

Prigent M, Dubois T, Raposo G, Derrien V, Tenza D, Rosse C, Camonis J, Chavrier P. 2003. ARF6 controls post-endocytic recycling through its downstream exocyst complex effector. J Cell Biol 163: 1111-1121.

Rappaport R. 1961. Experiments concerning the cleavage stimulus in sand dollar eggs. J Exp Zool 148: 81-89.

Renshaw MJ, Liu J, Lavoie BD, Wilde A. 2014. Anillin-dependent organization of septin filaments promotes intercellular bridge elongation and Chmp4B targeting to the abscission site. Open Biol 4: 130190.
Riggs B, Rothwell W, Mische S, Hickson GR, Matheson J, Hays TS, Gould GW, Sullivan W. 2003. Actin cytoskeleton remodeling during early Drosophila furrow formation requires recycling endosomal components Nuclear-fallout and Rab11. J Cell Biol 163: 143-154.

Riparbelli MG, Callaini G, Glover DM, Avides Mdo C. 2002. A requirement for the Abnormal Spindle protein to organise microtubules of the central spindle for cytokinesis in Drosophila. J Cell Sci 115: 913-922.

Robinett CC, Giansanti MG, Gatti M, Fuller MT. 2009. TRAPPII is required for cleavage furrow ingression and localization of Rab11 in dividing male meiotic cells of Drosophila. J Cell Sci 122: 4526-4534.

Schiel JA, Prekeris R. 2013. Membrane dynamics during cytokinesis. Curr Opin Cell Biol 25: 92-98.

Sechi S, Colotti G, Belloni G, Mattei V, Frappaolo A, Raffa GD, Fuller MT, Giansanti MG. 2014. GOLPH3 is essential for contractile ring formation and Rab11 localization to the cleavage site during cytokinesis in Drosophila melanogaster. PLoS Genet 10: e1004305.

Shim S, Kimpler LA, Hanson PI. 2007. Structure/function analysis of four core ESCRT-III proteins reveals common regulatory role for extreme C-terminal domain. Traffic 8: $1068-1079$.

Skop AR, Bergmann D, Mohler WA, White JG. 2001. Completion of cytokinesis in C. elegans requires a brefeldin Asensitive membrane accumulation at the cleavage furrow apex. Curr Biol 11: 735-746.

Skop AR, Liu H, Yates J III, Meyer BJ, Heald R. 2004. Dissection of the mammalian midbody proteome reveals conserved cytokinesis mechanisms. Science 305: 61-66.

Somers WG, Saint R. 2003. A RhoGEF and Rho family GTPase-activating protein complex links the contractile ring to cortical microtubules at the onset of cytokinesis. Dev Cell 4: 29-39.

Somma MP, Fasulo B, Cenci G, Cundari E, Gatti M. 2002. Molecular dissection of cytokinesis by RNA interference in Drosophila cultured cells. Mol Biol Cell 13: 2448-2460.

Stachowiak MR, Laplante C, Chin HF, Guirao B, Karatekin E, Pollard TD, O'Shaughnessy B. 2014. Mechanism of cytokinetic contractile ring constriction in fission yeast. Dev Cell 29: 547-561.

Steigemann P, Wurzenberger C, Schmitz MH, Held M, Guizetti J, Maar S, Gerlich DW. 2009. Aurora B-mediated abscission checkpoint protects against tetraploidization. Cell 136: 473-484.

Su KC, Takaki T, Petronczki M. 2011. Targeting of the RhoGEF Ect2 to the equatorial membrane controls cleavage furrow formation during cytokinesis. Dev Cell 21: 11041115.

Subramanian R, Wilson-Kubalek EM, Arthur CP, Bick MJ, Campbell EA, Darst SA, Milligan RA, Kapoor TM. 2010. Insights into antiparallel microtubule crosslinking by PRC1, a conserved nonmotor microtubule binding protein. Cell 142: 433-443.

Szafer-Glusman E, Giansanti MG, Nishihama R, Bolival B, Pringle J, Gatti M, Fuller MT. 2008. A role for very-longchain fatty acids in furrow ingression during cytokinesis in Drosophila spermatocytes. Curr Biol 18: 1426-1431.

Takeda T, Robinson IM, Savoian MM, Griffiths JR, Whetton AD, McMahon HT, Glover DM. 2013. Drosophila F-BAR 
protein Syndapin contributes to coupling the plasma membrane and contractile ring in cytokinesis. Open Biol 3: 130081.

Tang BL. 2012. Membrane trafficking components in cytokinesis. Cell Physiol Biochem 30: 1097-1108.

Thompson HM, Skop AR, Euteneuer U, Meyer BJ, McNiven MA. 2002. The large GTPase dynamin associates with the spindle midzone and is required for cytokinesis. Curr Biol 12: 2111-2117.

Toure A, Dorseuil O, Morin L, Timmons P, Jegou B, Reibel L, Gacon G. 1998. MgcRacGAP, a new human GTPase-activating protein for Rac and Cdc42 similar to Drosophila rotundRacGAP gene product, is expressed in male germ cells. J Biol Chem 273: 6019-6023.

von Dassow G. 2009. Concurrent cues for cytokinetic furrow induction in animal cells. Trends Cell Biol 19: 165-173.

Wakefield JG, Bonaccorsi S, Gatti M. 2001. The Drosophila protein asp is involved in microtubule organization during spindle formation and cytokinesis. J Cell Biol 153: 637-648.

Wang YL. 2005. The mechanism of cortical ingression during early cytokinesis: Thinking beyond the contractile ring hypothesis. Trends Cell Biol 15: 581-588.

Werner M, Munro E, Glotzer M. 2007. Astral signals spatially bias cortical myosin recruitment to break symmetry and promote cytokinesis. Curr Biol 17: 1286-1297.

Wienke DC, Knetsch ML, Neuhaus EM, Reedy MC, Manstein DJ. 1999. Disruption of a dynamin homologue affects endocytosis, organelle morphology, and cytokinesis in Dictyostelium discoideum. Mol Biol Cell 10: 225-243.

Wilson GM, Fielding AB, Simon GC, Yu X, Andrews PD, Hames RS, Frey AM, Peden AA, Gould GW, Prekeris R. 2005. The FIP3-Rab11 protein complex regulates recycling endosome targeting to the cleavage furrow during late cytokinesis. Mol Biol Cell 16: 849-860.
Wolfe BA, Takaki T, Petronczki M, Glotzer M. 2009. Pololike kinase 1 directs assembly of the HsCyk-4 RhoGAP/ Ect2 RhoGEF complex to initiate cleavage furrow formation. PLoS Biol 7: e1000110.

Wollert T, Wunder C, Lippincott-Schwartz J, Hurley JH. 2009. Membrane scission by the ESCRT-III complex. Nature 458: 172-177.

Wong R, Hadjiyanni I, Wei HC, Polevoy G, McBride R, Sem KP, Brill JA. 2005. PIP2 hydrolysis and calcium release are required for cytokinesis in Drosophila spermatocytes. Curr Biol 15: 1401-1406.

Xu H, Brill JA, Hsien J, McBride R, Boulianne GL, Trimble WS. 2002. Syntaxin 5 is required for cytokinesis and spermatid differentiation in Drosophila. Dev Biol 251: 294-306.

Yin HL, Janmey PA. 2003. Phosphoinositide regulation of the actin cytoskeleton. Annu Rev Physiol 65: 761-789.

Yuce O, Piekny A, Glotzer M. 2005. An ECT2-centralspindlin complex regulates the localization and function of RhoA. J Cell Biol 170: 571-582.

Zanin E, Desai A, Poser I, Toyoda Y, Andree C, Moebius C, Bickle M, Conradt B, Piekny A, Oegema K. 2013. A conserved RhoGAP limits M phase contractility and coordinates with microtubule asters to confine RhoA during cytokinesis. Dev Cell 26: 496-510.

Zhao WM, Fang G. 2005. MgcRacGAP controls the assembly of the contractile ring and the initiation of cytokinesis. Proc Natl Acad Sci 102: 13158-13163.

Zhu C, Jiang W. 2005. Cell cycle-dependent translocation of PRC1 on the spindle by Kif4 is essential for midzone formation and cytokinesis. Proc Natl Acad Sci 102: $343-$ 348.

Zhu C, Lau E, Schwarzenbacher R, Bossy-Wetzel E, Jiang W. 2006. Spatiotemporal control of spindle midzone formation by PRC1 in human cells. Proc Natl Acad Sci 103: 6196-6201. 


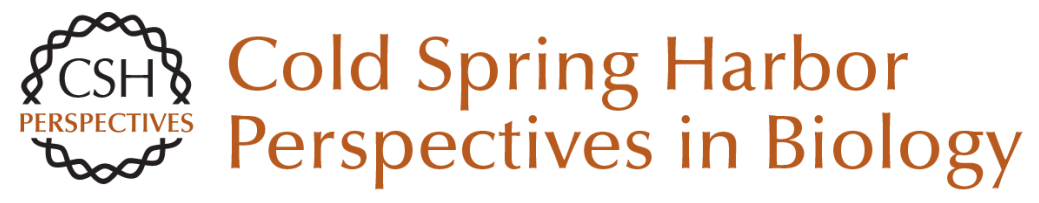

\section{Cytokinesis in Animal Cells}

Pier Paolo D'Avino, Maria Grazia Giansanti and Mark Petronczki

Cold Spring Harb Perspect Biol 2015; doi: 10.1101/cshperspect.a015834 originally published online February 13, 2015

\section{Subject Collection Mitosis}

Emergent Properties of the Metaphase Spindle Simone Reber and Anthony A. Hyman

Meiosis: An Overview of Key Differences from Mitosis

Hiroyuki Ohkura

Cytokinesis in Animal Cells

Pier Paolo D'Avino, Maria Grazia Giansanti and Mark Petronczki

The Centrosome and Its Duplication Cycle Jingyan Fu, Iain M. Hagan and David M. Glover

The Role of Model Organisms in the History of Mitosis Research

Mitsuhiro Yanagida
Chromosome Dynamics during Mitosis Tatsuya Hirano

The Centromere: Epigenetic Control of Chromosome Segregation during Mitosis Frederick G. Westhorpe and Aaron F. Straight

The Biochemistry of Mitosis Samuel Wieser and Jonathon Pines

Aurea Mediocritas: The Importance of a Balanced Genome

Gianluca Varetti, David Pellman and David J. Gordon

The Kinetochore

lain M. Cheeseman

For additional articles in this collection, see http://cshperspectives.cshlp.org/cgi/collection/

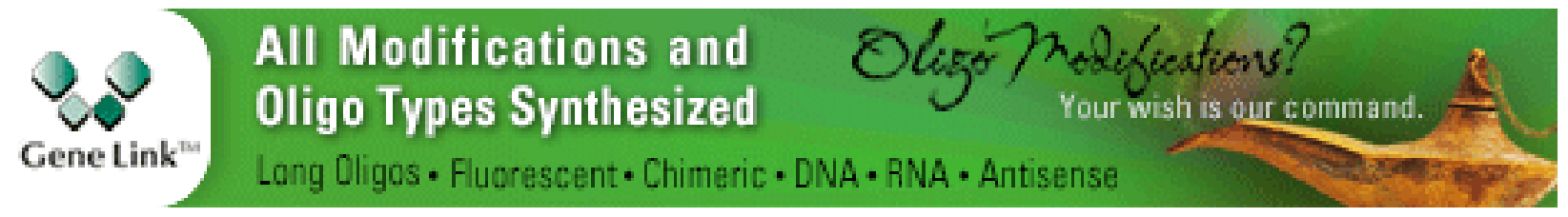

Copyright @ 2015 Cold Spring Harbor Laboratory Press; all rights reserved 